\title{
Durability Study of Geopolymer Paste Blended with Blast Furnace Slag
}

\author{
Debabrata Dutta ${ }^{1}$, Somnath Ghosh ${ }^{2}$ \\ 1. Research Scholar, Department of Civil Engineering, Jadavpur University, Kolkata- 700032, W.B, India., \\ 2. Professor, Dept. of Civil Engineering, Jadavpur University, Kolkata- 700032, W.B, India.
}

\begin{abstract}
In this program consequence of incorporating blast furnace slag on mechanical properties and durability of resulting fly ash geopolymer paste sample was investigated. The program consisted immersion of geopolymer samples having percentage blast furnace slag ranging from 10 to 20 of fly ash in a $10 \%$ magnesium sulfate solution up to a period of 15 weeks and evaluation of its resistance in terms visual appearance, change in weight and compressive strength at regular interval. Addition of blast furnace slag considerably improved mechanical properties and durability of geopolymers paste.
\end{abstract}

Keywords: Fly ash, Blast Furnace Slag, Geopolymer, Apparent porosity, Sorptivity, Compressive Strength, Durability.

\section{INTRODUCTION}

Geopolymeric binders $[1,2,3]$ are a types of inorganic binding agents whose common feature is alkaline activation of clinker or substances with latent hydraulic properties. Geopolymer shows potential more than ever in a few aggressive situations where Portland cement concretes are vulnerable [4]. The presence of zeolite-type substances is accountable for improving the properties of the alkali-activated binders, for example by rising their resistance to acids [5] or refining their ability to immobilize heavy metals [6,7]. Geopolymer materials are reported to exhibit high early strength, better durability and have almost no alkali-aggregate reaction [8]. These materials are therefore expected to be cement for the future [9]. Low calcium fly ash based geopolymer prepared with different activators have shown higher compressive strengths and excellent performance under different acidic and sulphate exposure [10-16]. It has also been reported to be highly resistant to elevated temperatures [17-19]. Geopolymer activated by a mixture of sodium hydroxide and sodium silicate solution shows higher compressive strength $[10,16,17]$. The addition of reasonable amount of minerals to a geopolymer can have significant enhancement on the geopolymer structure and properties. Temuujin et al. [20] recommended that the addition of calcium compounds $\mathrm{CaO}$ and $\mathrm{Ca}(\mathrm{OH}) 2$ improves mechanical properties of the fly ash-based geopolymers cured at ambient temperature. It was investigated that lime through pozzolanic reaction form a strong inter particle bond with amorphous silica and alumina [21]. Positive effect in conventional cement concrete by adding blast furnace slag has already been studied [22].

In this study blast furnace slag was used as a source material of calcium carbonate. The aim of the study was to predict the effect of addition of blast furnace slag as a supplementary material on mechanical properties and durability of fly ash based geopolymer pastes. Blast furnace slag by weight of $10 \%$ and $20 \%$ by fly ash was added to the fly ash based geopolymer paste. The assessment regarding durability of geopolymer materials was done by regular monitoring of its physical appearance, weight changes and compressive strength changes on exposure to $10 \%$ magnesium sulphate solution. Effects of apparent porosity and water sorptivity on weight and strength changes have also been predicted.

\section{A. Materials}

\section{EXPERIMENTAL}

For this research purpose low calcium Class F fly ash was collected from Kolaghat Thermal Power Plant near Kolkata, India. It had chemical composition as given in table-1. About $75 \%$ of particles were finer than 45 micron and Blaine's specific surface was $380 \mathrm{~m}^{2} / \mathrm{kg}$. The blast furnace slag used was in powdered form having specific gravity 2.8 , bulk density $1236 \mathrm{~kg} / \mathrm{m}^{3}$, consisting of $39.07 \% \mathrm{CaO}$. The average particle size of blast furnace slag was varied between $35 \mu$ to $65 \mu$. The chemical composition of blast furnace slag is given in Table- 2. Laboratory grade sodium hydroxide in pellet form (98 percent purity) and sodium silicate solution $\left(\mathrm{Na}_{2} \mathrm{O}=8 \%, \mathrm{SiO}_{2}=26.5 \%\right.$ and $65.5 \%$ water $)$ with silicate modulus $\sim 3.3$ and a bulk density of $1410 \mathrm{~kg} / \mathrm{m}^{3}$ was supplied by Loba Chemie Ltd, India. The alkaline activating solution was prepared by dissolving required quantity of sodium hydroxide pellets in water. The activator solution (sodium hydroxide and water) was left for 24 hours after that predetermined quantity of sodium silicate solution was added 3 hours before being used to manufacture geopolymer specimens. This activator solution had $\mathrm{Na}_{2} \mathrm{O}$ content equal to $8.0 \%$ of fly ash and 
$\mathrm{SiO}_{2} / \mathrm{Na}_{2} \mathrm{O}$ ratio equal to 1 . Water to fly ash ratio was of 0.33 . For preparation of exposure solution, Magnesium sulphate $\left(\mathrm{MgSO}_{4}\right)$ in powder form with $99 \%$ purity was directly dissolved in water to get $10 \%$ magnesium sulfate solution (by weight).

Table-1. Composition of fly ash (\% mass)

\begin{tabular}{|l|c|c|c|c|c|c|c|c|c|c|c|}
\hline $\begin{array}{l}\text { Chemical } \\
\text { composition }\end{array}$ & $\mathrm{SiO}_{2}$ & $\mathrm{Al}_{2} \mathrm{O}_{3}$ & $\mathrm{Fe}_{2} \mathrm{O}_{3}$ & $\mathrm{TiO}_{2}$ & $\mathrm{CaO}$ & $\mathrm{MgO}$ & $\mathrm{K}_{2} \mathrm{O}$ & $\mathrm{Na}_{2} \mathrm{O}$ & $\mathrm{SO}_{3}$ & $\mathrm{P}_{2} \mathrm{O}_{5}$ & $\mathrm{LOI}^{2}$ \\
\hline Fly ash & 56.01 & 29.8 & 3.58 & 1.75 & 2.36 & 0.30 & 0.73 & 0.61 & $\mathrm{Nil}$ & 0.44 & 0.40 \\
\hline
\end{tabular}

Table-2 Composition of blast furnace slag (\% mass)

\begin{tabular}{|l|c|c|c|c|c|c|c|}
\hline Chemical composition & $\mathrm{CaO}$ & $\mathrm{MgO}$ & $\mathrm{Fe}_{2} \mathrm{O}_{3}$ & $\mathrm{MnO}$ & $\mathrm{Al}_{2} \mathrm{O}_{3}$ & $\mathrm{SiO}_{2}$ & $\begin{array}{c}\text { Loss on } \\
\text { ignition }\end{array}$ \\
\hline Blast Furnace Slag & $39.07 \%$ & $8.95 \%$ & $1.87 \%$ & $0.44 \%$ & $15.18 \%$ & $30.26 \%$ & $0.04 \%$ \\
\hline
\end{tabular}

Table 3. Details of the geopolymer test specimens

\begin{tabular}{|c|c|c|c|c|c|}
\hline $\begin{array}{c}\text { Sample } \\
\text { ID }\end{array}$ & $\begin{array}{c}\mathrm{Na}_{2} \mathrm{O} \\
\text { content in } \\
\text { activator }(\%)\end{array}$ & $\begin{array}{c}\mathrm{SiO}_{2} \text { content } \\
\text { in activator } \\
(\%)\end{array}$ & $\begin{array}{c}\text { Blast Furnace } \\
\text { Slag }(\% \text { by } \\
\text { wt. of fly ash) }\end{array}$ & $\begin{array}{c}\text { Type of } \\
\text { specimen }\end{array}$ & $\begin{array}{c}\text { Water / fly ash } \\
\text { ratio }\end{array}$ \\
\hline GP1 & 8 & 8 & 0 & Paste & 0.33 \\
\hline GC1 & 8 & 8 & 10 & Paste & 0.33 \\
\hline GC2 & 8 & 8 & 20 & Paste & 0.33 \\
\hline
\end{tabular}

\section{B. Preparation of specimens and testing}

Fly ash, with or without blast furnace slag was mixed with predetermined quantity of activator solution for 5 minutes in a Hobart mixer. The geopolymers mix exhibited a thick sticky nature with low workability. The mix was then transferred into 50 x 50 × $50 \mathrm{~mm}$ steel cubes. Table vibration was provided for 2 minutes to expel any entrapped air. After 60 minutes, the cubes were cured in an oven for a period of 48 hours at $85 \mathrm{oC}$ and then allowed to cool inside the oven [7]. Specimens were demoulded and stored at room temperature at a dry place before testing. Some specimen data of the present study are given in the table- 3 .

The geopolymer specimens were immersed in $10 \%$ magnesium sulphate solution for 15 weeks after 3 days from casting. Specimens were tested for physical changes, weight changes and compressive strength changes at regular intervals. An optical microscope was used for observing surface changes. In support of each data point, ten replicate specimens were tested. Apparent porosity and sorptivity tests were conducted as per the procedure followed by Thokchom et al. [13]. Unexposed specimens were subjected to water absorption, apparent porosity, water sorptivity and compressive strength tests as well, to assess the pore characteristics.

\section{RESULT AND DISCUSSION}

\section{A. Unexposed geopolymer specimens}

\section{a. Apparent porosity and Water absorption}

To evaluate the pore characteristics apparent porosity and water absorption of the geopolymer specimens have been determined. Fig. 1 and Fig. 2 presents the apparent porosity and water absorption for the specimens. Specimens have exhibited decreasing apparent porosity with additional blast furnace slag. GP1 specimen without blast furnace slag showed apparent porosity of $24.3 \%$ while for GC2 specimen with $10 \%$ blast furnace slag, the apparent porosity decreased to $22.93 \%$. Decreasing trend in water absorption is observed with additional blast furnace slag in geopolymer paste. Minimum water absorption obtained for pastes was for GC2 with a value of $10.89 \%$. As blast furnace slag contains a large amount of calcium content this produces $\mathrm{Ca}+$ ions. The $\mathrm{Ca}+$ ions may act as a charge balancer of aluminum atoms [23]. Whereas unreacted blast furnaces slag particles may act as reinforcing agent. Again a portion of blast furnace slag may possibly enter into the Si-O-Al$\mathrm{O}$ structure. These phenomena perhaps leave a favorable impact on the pore morphology of geopolymer. 


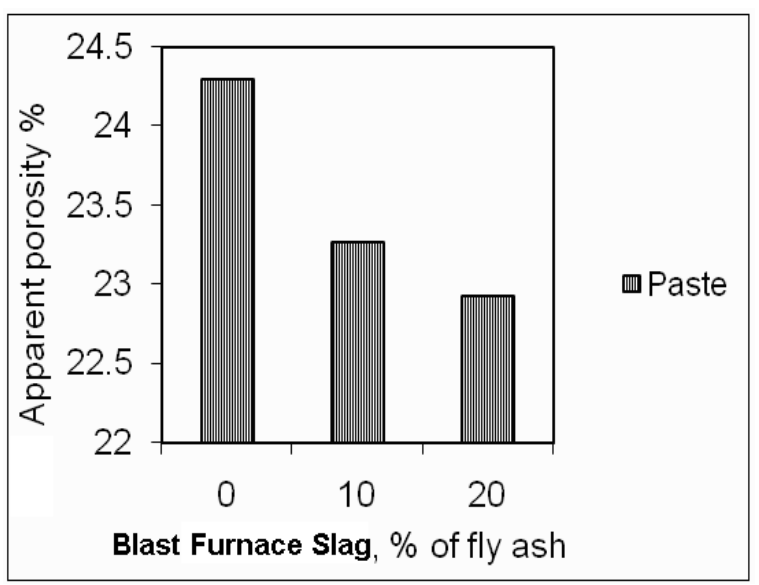

Figure 1. Apparent porosity of Geopolymer specimens

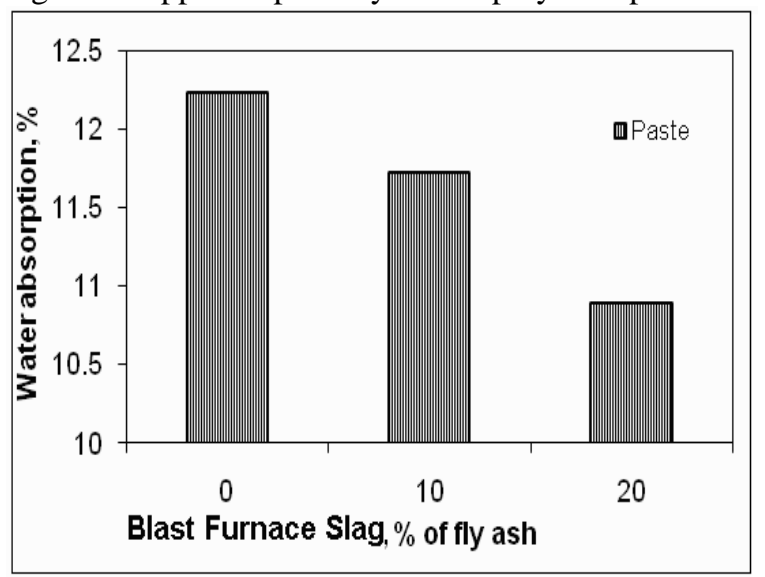

Figure 2. Water absorption of Geopolymer specimens

\section{b. Water sorptivity}

Sorptivity is considered to be an important property associated with durability of cement concrete specimens [24]. Due to the capillary rises the water ingress into a non saturated cement concrete. The test for sorptivity consists of measuring the capillary sorption of water with time. In this study curves for cumulative absorption of water plotted against square root of time as shown in Fig.3.The slope for initial linear portion for each of these curves indicates the sorptivity values as given in Fig. 4 presents sorptivity results for the geopolymer paste specimens. Fig. 3 exhibits capillary sorption is initially fast and considerably low down afterward for every geopolymer specimen.It is evident that cumulative sorption is highest for GP1 specimen. Similarly GC2 indicates lowest cumulative sorption of water. But it should be mentioned that rate of suction is higher for blast furnace slag blended geopolymer as suction rate through surface is accelerated .It may be due to reduction in average pore sizes.

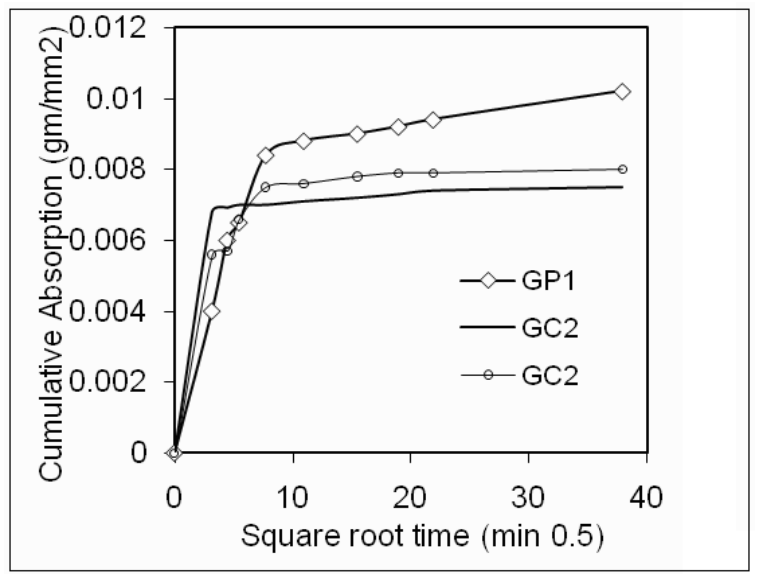

Figure 3. Trend of cumulative sorption of water for geopolymer specimens 


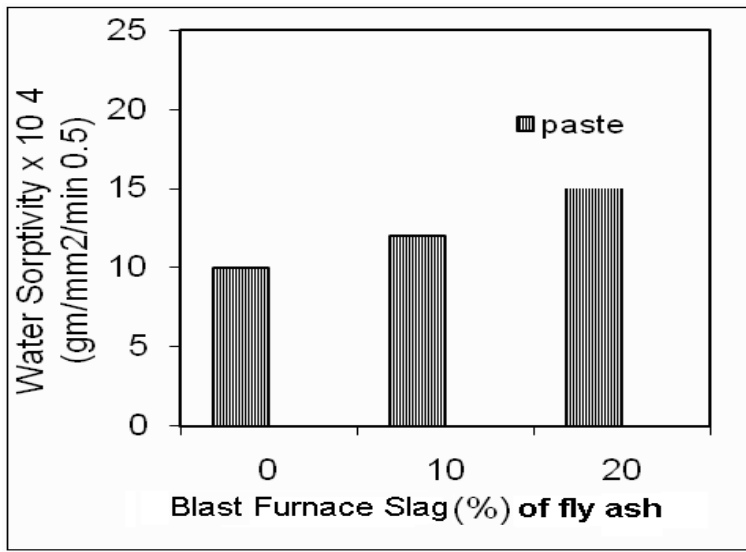

Figure 4.Water sorptivity of geopolymer specimens

\section{B. Durability in Magnesium sulphate a. Visual observation}

Optical microscope, accuracy $.02 \mathrm{~mm}$, Zoom capacity of $10 \mathrm{X}$ has been used to monitor the physical appearance of geopolymer specimens after exposure to magnesium sulphate solution. Geopolymer paste specimen without blast furnace slag got white crystal deposits after exposure which were very soft but with time being it became harder. Specimen containing blast furnace slag in no case got white deposits. The white reaction product may be magnesium aluminosilicate [25]. This white deposit has been also reported by some authors [12, 28, 29]. Here the product has been tested through SEM and EDAX .The Scanning Electron Microscopy (Fig. 6) depicts the presence of regular structure on the surface of deposits which supports the crystal nature. The EDAX peaks (Fig. 7) indicates the existence of Magnesium, Silicon and Aluminum in this outcome. Possibly the decrease in the mean and median size causes significant reduction in the penetration of solution in geopolymeric structure. Images of surfaces for paste specimens as seen under an optical microscope after 6 weeks in magnesium sulphate solution are shown in Fig. 5. These images clearly reveal the surface deposits for sample without blast furnace slag.

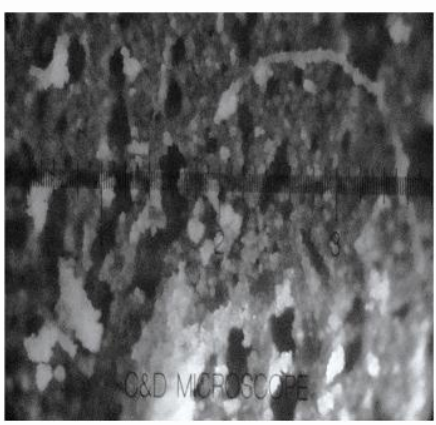

GP1

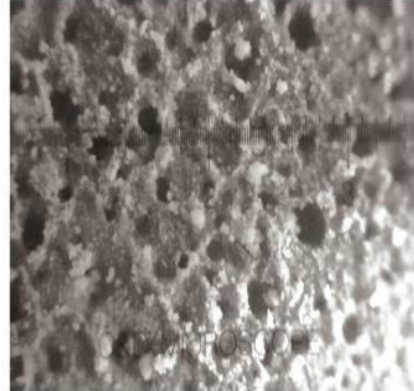

GC1



GC2

Figure 5. Geopolymer paste specimens after 6 weeks in $10 \%$ magnesium sulphate solution

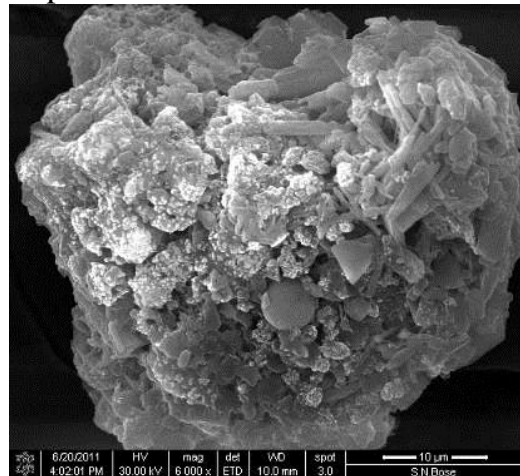

Figure 6. SEM Image of white deposit under $400 \mathrm{x}$ zoom 


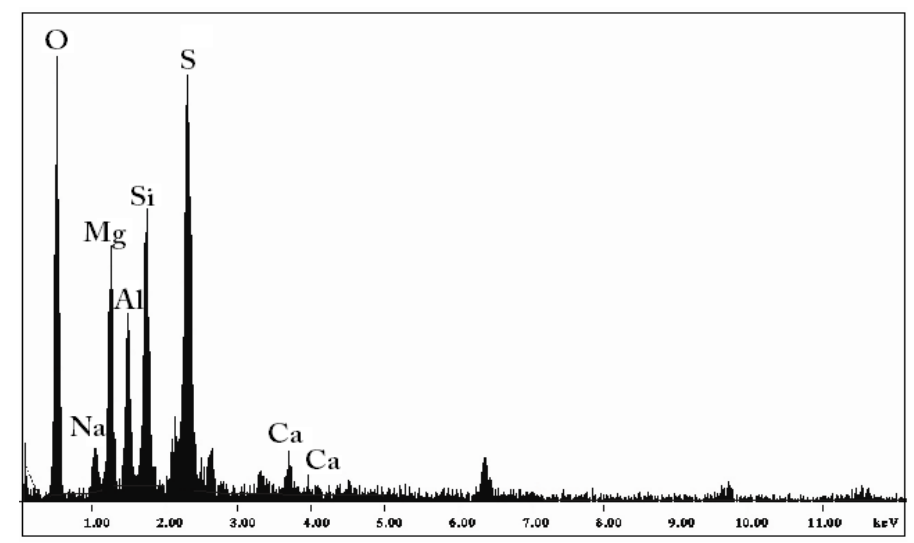

Figure 7. EDAX of white deposite

\section{b. Weight changes}

Weights for exposed specimens were measured at regular intervals in saturated surface dry condition after washing and removal of surface deposits. Specimens are cleaned in running cold water for around five minutes and wiped dry with clean lint free cloth and then blown with clean dry air for around 5 minutes. The trends of weight changes for the alkali activated fly geopolymer specimens are presented in Fig. 8. Speedy increases in weight took place for all paste specimens up to 1 week of exposure. This is due to absorption of sulphate solution into the specimens. No further increase was shown for blended specimens after the initial rise. Weight gain continued gradually for 50 days in specimen GP1 (without blast furnace slag).It indicates continuous penetration of sulphate solution in addition to formation of reaction products due to interaction of geopolymer material with the exposure solution [28]. Weights of specimens were remaining almost constant up to the end of test where the specimens without supplementary blast furnace slag began to decrease beyond 50 days of exposure. The drop in weight could be due to migration of alkalis from the specimens into the solution and also due to breakdown and dissolution of some reaction products. Final weight for all the samples was higher than initial one. It can be expected from the trend for weight change at later stages of exposure that further exposure beyond 15 weeks could lead to weight losses in the specimens without blast furnace slag. Comparing Fig. 1 with Fig. 8 it may be concluded in this way that the specimen having much apparent porosity allows more intrusion of sulfate solution which causes reaction within the structure of the specimen. This newly built reaction product within the internal voids is accused for weight gaining. The loss is due to the expulsion of this reaction product later on. Performance of paste specimens incorporated with blast furnace slag enhanced.

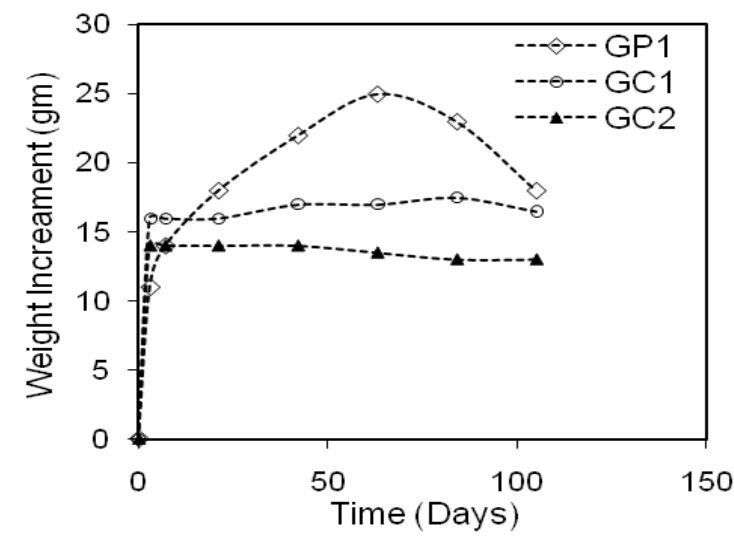

\section{c. Compressive strength changes}

Figure 8. Weight changes for geopolymer paste specimens

Blast furnace slag addition gives quick hardening behavior which minimize the time of hardening of fly ash based geopolymer. Higher calcium content may results in faster geopolymerisation due to the formation of semi-crystalline Ca-Al-Si gel [29]. The compressive strength of the geopolymer paste was evaluated after 3 days of synthesis. Ten specimens for each mix composition were subjected to compression in a digital compressive strength testing machine and the average is reported. GP1 specimen prepared without blast furnace slag has a compressive strength of $37 \mathrm{MPa}$. Noteworthy increases of strength occurred for GC2 specimen (43 MPa) which contained $20 \%$ blast furnace slag. Similarly, the compressive strength is increased to (39 MPa) with additional blast furnace slag of $10 \%$.The results clearly indicate successive increment in compressive strength of the 
specimens with higher blast furnace slag addition. But for this research the aim is to evaluate the residue of strength at aggressive condition with time being as a percentage of initial strength.

The variation of residual compressive strength (as shown in Fig. 9) over the entire period of exposure in $10 \%$ magnesium sulphate solution was monitored. Compressive strength of sulphate exposed specimen containing no additive reduced with time after getting an initial peak. Bakharev [16] states that the loss of strength due to migration of alkalis from the specimens and also due to diffusion of calcium and sulphur near the surface region. For all the cases of blended specimens a almost constant strength feature was observed. After 15 weeks in sulphate solution, paste specimens recorded residual strengths of $81 \%, 99.2 \%$ and $99.7 \%$ for GP1, $\mathrm{GC} 1$ and GC2 specimens respectively. Here the residual compressive strength of geopolymer specimens is significantly influenced by the porosities. Though the trend shows drop in strength is obvious for all the cases but specimens with blast furnace slag will remain much intact under sulphate exposure.



Figure 9. Residual strength for geopolymer paste

\section{CONCLUSION}

Based on the results of the present experimental investigation, following conclusions are drawn

1. Addition of blast furnace slag decrease apparent porosity and water absorption of fly ash based geopolymer pastes.

2. Geopolymer paste incorporated with blast furnace slag resulted in higher sorptivity but cumulative sorption is highest for GP1 specimen which is not blended.

3. Compressive strength of blast furnace slag added geopolymer pastes were exhibited higher strength.

4. Blast furnace slag added geopolymer pastes resulted in higher residual strength after exposure to $10 \%$ magnesium sulphate solution.

5. Geopolymer paste with additional blast furnace slag showed enhanced performance in exposure to magnesium sulphate solution.

\section{REFERENCES}

[1] A. Fernandez-Jimenez and A. Palomo., Activation of fly ashes: A general view, Fly ash, Blast Furnace Slag, Slag, and Natural Pozzolans in Concrete, Proceedings Eighth International Conference, Las Vegas, USA, (2004) 351-366.

[2] H. Xu, G.C. Lukey, and J.S.J. van Deventer., The activation of class C, class F fly ash and blast furnace slag using geopolymer, Fly ash, Blast Furnace Slag, Slag, and Natural Pozzolans in Concrete, Proceedings Eighth International Conference, Las Vegas, USA., (2004) 797-820

[3] Khon Kaen, Engineering Properties of Mae Moh Fly Ash Geopolymer Concrete Thailand, Smith Songpiriyakij King Mongkut's Institute of Technology, North Bangkok, Thailand, May 24-25, 2006.

[4] Song X.J , Marosszeky M, Brungs M, Munn R, Durability of fly ash based Geopolymer concrete against sulphuric acid attack , 10 DBMC International Conferences on Durability of Bulding Materials and Components, Lyon, France, (2005) 17-20 April .

[5] Thakur Ravindra N, Ghosh Somnath, Effect of mix composition on compressive strength and microstructure of fly ash based geopolymer composites, 4 (4) (2009) 68-74.

[6] D. Hardjito and B. V. Rangan., Development and properties of low-calcium fly ash -based geopolymer concrete , Research Report GC , Faculty of Engineering , Curtin University of Technology , Perth , Australia , (2005) 1-130.

[7] Thakur Rabindra N, Ghosh Somnath, Fly ash based Geopolymer composites, Proceedings of 10th NCB International seminar on Cement and bulding materials, NEW Delhi , India, 3 (2007) 442-45

[8] J. Davidovits, Properties of geopolymer cements, Proceedings of the first International conference on alkaline cements and concretes, 1 (1994) 131-149.

[9] A.Palomo, M.W. Gruztek, M.T. Blanco, Alkali activated fly ashes. A cement for the future, Cement and Concrete Research, 29 (1999) 1323-1329.

[10] T. Bakharev, Resistance of geopolymer materials to acid attack, Cement and Concrete Research, 35 (2005) 658-670.

[11] X.J. Song, M. Marosszeky, M.Brungs. Munn, Durability of fly ash based geopolymer concrete against sulphuric acid attack, 10 DBMC International conference on durability of building materials and components, (2005), Lyon, France

[12] S. Thokchom, P. Ghosh, S. Ghosh, Influence of alkali content on performance of geopolymer mortars in magnesium sulphate, Arabian J. for Science and Engineering, Accepted for publication, 2011. 
[13] S.Thokchom, P. Ghosh, S. Ghosh, Porosity and sorptivity on performance of fly ash based geopolymer mortars in Nitric acid, Int. J Applied Engg. Research 4(11) (2009) 2085-2092.

[14] Fernandez-Jiminez, I.Garcia-Lodeiro, A.Palomo, Durability of alkali activated fly ash cementitious materials, J. Mater Sci., 42 (2007) 3055-3065

[15] S.E. Wallah, B.V. Rangan, Low calcium fly ash based geopolymer concrete: Long term properties, Research report GC2, (2006), Curtin University of Technology, Australia.

[16] T. Bakharev, Durability of geopolymer materials in sodium and magnesium sulphate solutions", Cement and Concrete Research, 35 (2005) 1233-1246.

[17] T. Bakharev, Geopolymeric materials prepared using class F fly ash and elevated temperature curing, Cement and Concrete Research 35 (2005) 1224-1232.

[18] T.Bakharev, Thermal behaviour of geopolymers prepared using class F fly ash and elevated temperature curing, Cement and Concrete Research, 36 (2006) 1134-1147.

[19] D. L.Y. Kong, J.G. Sanjayan, Effect of elevated Effect of elevated temperatures on geopolymer paste, mortar and concrete, Cement and Concrete Research, 40, (2010) 334-339.

[20] Temuujin J, van Riessen A, Williams R., Influence of calcium compounds on the mechanical properties of fly ash geopolymer pastes, J Hazard Mater, 167( 1-3) (2009 82-88.

[21] Akshaya Kumar Sabat, Radhikesh P. Nanda, Effect of Blast Furnace Slag on strength and durability of Rice husk ash stabilised expansive soil, International Journal of Civil and Structural Engineering, 1(4) (2011)

[22] Bahar Demirel, The effect of the using waste Blast Furnace Slag as fine sand on the mechanical properties of the concrete, International Journal of the Physical Sciences, 5(9) (2010) 1372-1380.

[23] Fernando Pacheco-Torgal, João Castro-Gomes, Said Jalali, Alkali-activated binders: A review Part 1. Historical background, terminology, reaction mechanisms and hydration products, Construction and Building Materials, 22 (7) (2008)1305-1314.

[24] Sabir B.B, Wild S, O'Farrel M, A water sorptivity test for mortar and concrete, Materials and Structures, 31 (1998) 568-574.

[25] Frantisek Skvara, Tomas Jilek, Lubomir Kopecky, Geopolymer Materials Based on Fly Ash, Ceramics- Silicaty, 49(3) (2005) 195204.

[26] A.Allahverdi, F. Skvara, Sulfuric acid attack on hardened paste of geopolymeric cements part 1,Mechanism of corrosion at relatively high concentrations, Ceramics-Silikaty, 49 (4) (2005).225-229.

[27] F. Rendell and R. Jauberthie, The deterioration of mortar in sulphate environments, Cement \& Concrete Research, 13 (1999) 321 327.

[28] S.Thokchom, D.Dutta, S.Ghosh, Effect of Incorporating Silica Fume in Fly Ash Geopolymers, World Academy of Science, Engineering and Technology, 60 (2011) 243-247

[29] Yip, C.K., Van Deventer, J.S.J. Effect of granulated blast furnace slag on geopolymerisation, Proceedings of 6th World Congress of Chemical Engineering, Melbourne, Australia, 23-27 September 1501. 